\title{
NARRAR PARA CONTAR SUA HISTÓRIA: REPRESENTAÇÃO DISCURSIVA DE REMANESCENTES QUILOMBOLAS
}

\author{
NARRATING TO TELL YOUR OWN STORY: \\ DISCOURSIVE REPRESENTATION OF \\ QUILOMBO REMNANTS
}

\author{
Josinaldo Pereira de Paula ${ }^{1}$, Maria Eliete de Queiroz ${ }^{2}$
}

\begin{abstract}
RESUMO: Este trabalho investiga Representações discursivas (Rds) na narrativa do lobisomem, contada por remanescentes quilombolas de Portalegre/RN, em Souza, Mendes e Fonseca (2011). Recorremos aos estudos da Linguística Textual, situando a abordagem da Análise Textual dos Discursos (ATD), com base em Adam (2011) e em estudos de Rodrigues, Passeggi e Silva Neto (2010), Passeggi et al. (2010), Rodrigues et al. (2012), Queiroz (2013). Reportamo-nos, também, aos estudos da esquematização em Grize (1990, 1996), Passeggi (2001). A noção de representação discursiva é apresentada pela ATD e constitui a dimensão semântica do texto. Neste artigo, as Rds construídas por meio das categorias da referência/referenciação, da predicação, da localização e da aspectualização por meio de elementos linguístico-discursivos que viabilizam a construção de sentido do texto. Interpretamos as Rds de religiosos, corajosos e a de medo, por ser sorteado para o exército brasileiro, mostrando o terror que foi a segunda guerra mundial para essas comunidades.
\end{abstract}

PALAVRAS-CHAVE: Representações discursivas. Análise textual-discursiva. Narrativa. Narrativa do lobisomem. Remanescentes quilombolas.

ABSTRACT: This work investigates Discursive Representations (Rds) in the werewolf narrative told by quilombo remnants from Portalegre/RN in Souza, Mendes and Fonseca (2011). We rely on the studies of Text Linguistics, situating the approach of Discourse Textual Analysis (DTA), based on Adam (2011) and on the studies of Rodrigues, Passeggi and Silva Neto (2010), Passeggi et al. (2010), Rodrigues et al. (2012), Queiroz (2013). We report, also, to the studies of schematization on Grize (1990, 1996), Passeggi (2001). The notion of discursive representation is presented by DTA and it constitutes the semantic dimension of the text. In this article, the Rds constructed by the categories of reference/referentiation, predication, location and aspectualization by linguistic-discursive elements that enable the meaning construction of the text. We interpret the Rd of religious, brave and of fear of being called to the Brazilian army, showing the terror that was the World War II for these communities.

KEYWORDS: Discursive representations. Textual-discursive analysis. Narrative. Narrative of the werewolf. Remaining quilombolas.

\footnotetext{
${ }^{1}$ Doutorando do Programa de Pós-graduação em Letras (PPGL) pela UERN.

${ }^{2}$ Professora doutora do Departamento de Letras Estrangeiras (DLE) e do Programa de Pós-graduação em Letras (PPGL) da UERN.
} 


\section{Introdução}

Este artigo é um recorte da dissertação de mestrado "Representações discursivas em narrativas contadas por remanescentes quilombolas de Portalegre/RN", em que analisamos diversas Representações discursivas (Rds), em quatro narrativas contadas por remanescentes quilombolas de quatro comunidades diferentes, situadas no município de Portalegre no estado do Rio Grande do Norte. Usamos como corpus o ebook A fala dos remanescentes quilombolas de Portalegre do Brasil, organizado por Souza, Mendes e Fonseca (2011), gravado no ano 2000, com a transcrição de seis (06) inquéritos de fala em eventos reais de comunicação entre um entrevistador (E) e moradores das comunidades remanescentes quilombolas do Pêga, Engenho Novo e Arrojado da cidade de Portalegre/RN. Como recorte desse Corpus, selecionamos a narrativa do lobisomem que está localizada no inquérito 04, entre as linhas $238 \mathrm{~d}$ a $505 \mathrm{~d}^{3}$, sendo contada por um casal: um homem de oitenta e quatro anos e uma mulher de oitenta e um anos, que chamamos, neste artigo, respectivamente de H84 e M81.

Este casal relata três enfrentamentos que tiveram com um Lobisomem. No primeiro momento da narração, H84 afirma ter brigado duas vezes com a fera, na sua mocidade, quando vinha da casa da namorada, tendo apanhado e fugido, da primeira vez, e vencido na segunda, por ter se armado com um bastão de madeira. Na segunda parte da história, M81 afirma ter enfrentado essa criatura na frente de sua casa e a colocado para fugir com uma foice.

Nosso trabalho tem como base os estudos da Análise Textual dos discursos (ATD) de Adam (2011), com as contribuições de Rodrigues, Passeggi e Silva Neto (2010), Passeggi (2001), Passeggi et al. (2010), Rodrigues et al. (2012), que trouxeram para o cenário da Linguística Textual (LT) uma nova perspectiva teórica e metodológica, que foram os estudos da Análise Textual dos discursos (ATD) relacionando o texto e o discurso. Nesse sentido, Adam (2011) faz uma articulação entre a LT e a análise do discurso (AD), compreendendo a relação semântico-gramatical por meio dos elementos linguístico-discursivos que viabilizam a construção de sentido do texto.

A categoria textual de análise com a qual trabalhamos está localizada no Nível Semântico (N6) com a noção de Representação discursiva (Rd), proposta por Adam

\footnotetext{
${ }^{3}$ Esse código é usado pelos autores do corpus, a letra "d" significa o número do inquérito de fala em que essa contagem de linha está inserida.
} 
(2011) no seu esquema 4. Para o autor, todo locutor em um determinado discurso, oral ou escrito, constrói uma $\mathrm{Rd}$, ou seja, imagens do alocutário e do tema tratado. Nesta perspectiva, este artigo tem como objetivo analisar a representação discursiva dos remanescentes quilombolas.

As narrativas ficcionais são famosas por contarem histórias fantásticas com seres mitológicos investidos de poderes, espertezas e tamanhos fora da realidade. Mas o que acontece quando dentro dessas narrativas são encaixados vestígios de uma narrativa real escondida e esquecida por muitos? É o que acontece durante a narrativa do lobisomem, contada pelo casal remanescente quilombola da cidade de Portalegre/RN. Esse casal, ao contar a narrativa do lobisomem, revela na sua história uma semelhança com a ficção, o que leva a crer que a realidade de luta e terror vivida por ele exponha um fio entre o imaginário e o real, de um tempo de exploração do povo descendente de escravos na cidade de Portalegre/RN.

Como metodologia de análise, selecionamos excertos da narrativa do lobisomem e, por meio das categorias da referência/referenciação e da predicação, aspectualização e localização, interpretamos a representação discursiva dos remanescentes quilombolas.

Nosso artigo está dividido em quatro partes. Na introdução, apresentamos uma discussão inicial acerca do conteúdo teórico do trabalho e indicamos os objetivos e os aspectos metodológicos com os quais alcançamos estes objetivos. No referencial teórico, abordamos alguns conceitos sobre a análise textual dos discursos e as representações discursivas. Na análise dos dados, interpretamos as Rds dos remanescentes quilombolas por meio de excertos do corpus. Por fim, a conclusão, em que retomamos o objetivo e apresentamos nossos resultados e conclusões.

\section{Análise Textual dos Discursos (ATD) e representações discursivas (Rds)}

A ATD é um campo teórico-metodológico que articula a Linguística textual (LT) e a Análise do discurso (AD). Os estudos começaram no Brasil com a obra de Jean-Michael Adam, $A$ linguística textual: Introdução à análise textual dos discursos. Diante da articulação entre texto e discurso, Adam (2011, p. 43) afirma que "é sobre novas bases que propomos, hoje, articular uma linguística textual desvencilhada da gramática de texto e uma análise de discurso emancipada da Análise de Discurso Francesa (ADF)". Para Adam (2011, p. 63), objetivo é "teorizar e descrever os encadeamentos de enunciados elementares no âmbito da unidade de grande 
complexidade que constitui um texto". Assim, entendemos que a ATD, através da descrição das unidades e o encadeamento dos enunciados formam um determinado discurso, em um determinado contexto sociocultural, buscando um objetivo específico na interação entre os sujeitos. $\mathrm{O}$ autor anuncia que as relações textuais discursivas são formadas co(n)textualmente e explica:

escrevemos "co(n)texto" para dizer que a interpretação de enunciados isolados apoia-se tanto na (re)construção de enunciados à esquerda e/ou à direita (cotexto) como na operação de contextualização, que consiste em imaginar uma situação de enunciação que torne possível o enunciado considerado. (ADAM, 2011, p. 52).

Como exposto pelo autor, as escolhas linguísticas co-textualizadas determinam sentidos diversos, dependendo da ordem do léxico colocado pelo autor do texto com a intenção específica em uma situação discursiva. Já a contextualização é o lugar, o tempo e as pessoas envolvidas no discurso, pois os sentidos não dependem apenas da materialidade linguística do texto, mas de todos esses fatores envolvidos que tornam possível a situação discursiva e a interação. É possível observamos no esquema 4 de Adam (2011, p.61) esta relação entre os níveis de análise de discurso e do texto.

\section{ESQUEMA 4}

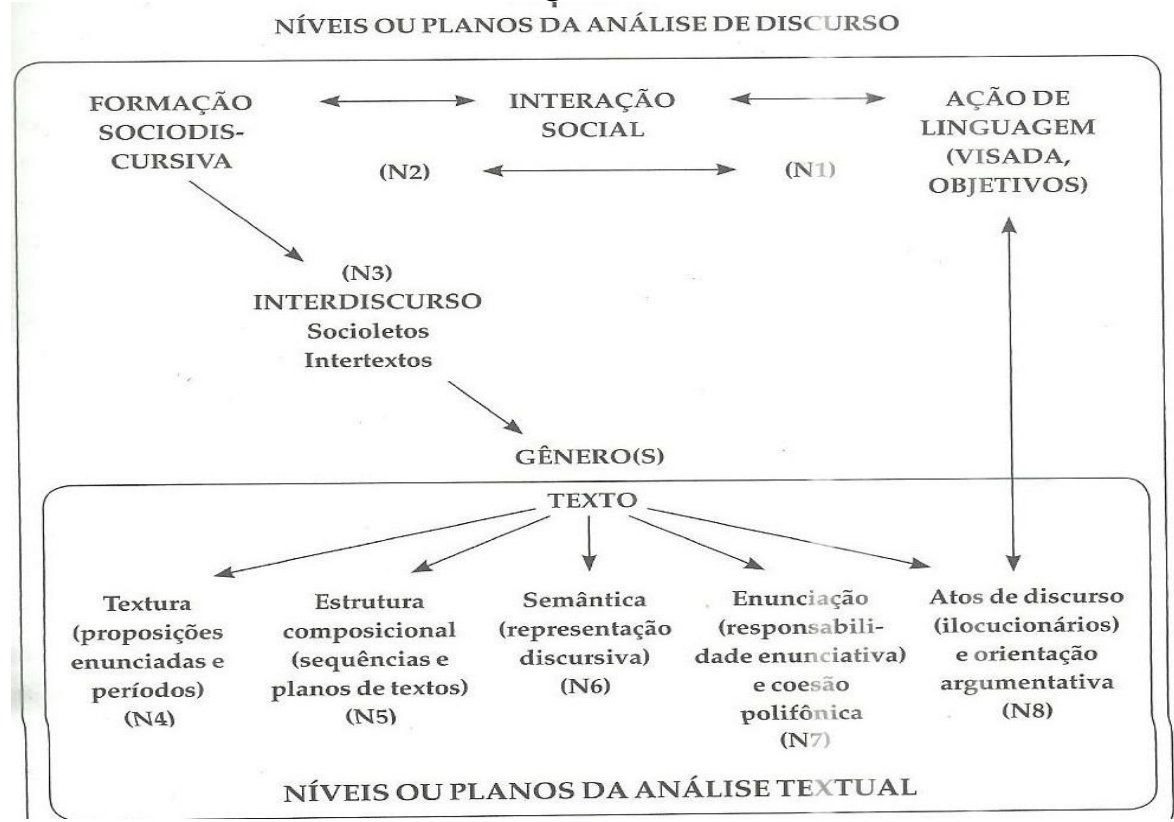

Níveis da análise de discurso e níveis da análise textual

Fonte: Rodrigues, Passeggi e Silva Neto (2011, p. 61).

No esquema 4, visualizamos um quadro maior que está relacionado aos níveis de análise de discurso e dentro deste quadro, em sua base, está o que se refere aos níveis de 
análise textual. Assim, os níveis textuais direcionam o locutor para um nível maior: o discurso. Observamos, também, um jogo de setas com pontas duplas que nos levam a entender que a relação entre o texto e o discurso ocorre de forma circular.

Os Níveis 1 e 2 são: (N1) a ação de linguagem (visada, objetivos), ou seja, o momento em que o locutor usa a linguagem para formar um discurso, oral, escrito, verbal ou não verbal. O (N2) é a interação social, uma vez que o discurso, para alcançar seu objetivo, precisa estar em interação com o outro e sua formação discursiva, que “determina o que pode ser dito (articulado sob a forma de uma arenga, um sermão, um panfleto, uma exposição um programa etc.) a partir de uma posição dada numa conjuntura". (PÊCHEUX; FUCHS, 1997 apud MAZZOLA, 2009, p.13). É respeitando a formação discursiva de cada espaço que os discursos são construídos com determinados fins e em contextos específicos.

No nível três (N3) o autor coloca o interdiscurso, os socioletos e o intertexto, visto que o interdiscurso atravessa todos os discursos por meio do texto que se materializa nos gêneros textuais, nas múltiplas esferas sociais de comunicação em diversas variações de uso da linguagem. Os gêneros estão no plano discursivo, pois são eles que direcionam para os níveis de análises do texto, enquanto mediador.

Ainda no esquema 4, chegamos nos planos de análise textual em que Adam (2011) os colocam em cinco níveis de análises. Nosso foco neste trabalho está no nível semântico (N6), especificamente com a noção de representação discursiva. O conceito de representação discursiva está relacionado com a noção de proposição-enunciado que é a base para os estudos da ATD.

Adam (2011, p.111) apresenta um esquema que mostra a proposição-enunciado em três dimensões complementares.

Vejamos o esquema.

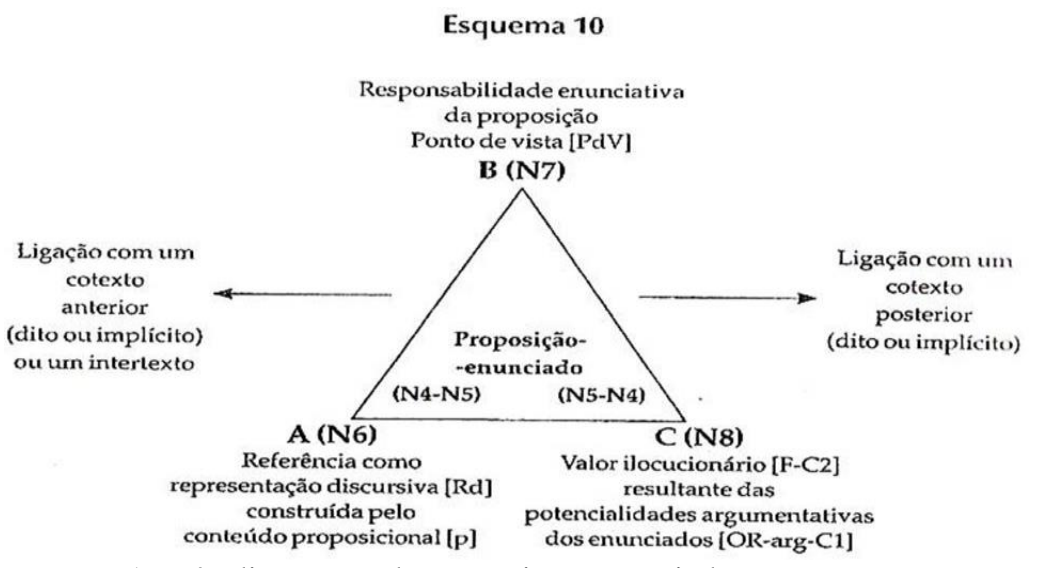

As três dimensões da proposição-enunciado

Fonte: Adam (2011). 
O formato triangular no "Esquema 10" tem no centro a proposição-enunciado com relação direta aos níveis (N4) e (N5) que são a textura, ou seja, as próprias proposições, os períodos e a composição das sequências e planos de textos. As setas ao lado se referem à construção dos cotextos, sendo eles anteriores, ou seja, respondem a outro enunciado ou posteriores que chamam os alocutários para responder ou reconstruí-los e, assim, formar o discurso.

Nas pontas do triângulo encontramos três níveis: a responsabilidade enunciativa ou Ponto de Vista (PdV), localizada em [B] (N7), que para Adam (2011, p.117) “o grau de responsabilidade enunciativa de uma proposição é suscetível de ser marcado por um grande número de unidades da língua". Em seguida, observamos a referência como a Representação discursiva (Rd) em [A], construída pelo conteúdo proposicional. Por fim, [C] com o valor ilocucionário resultante das potencialidades argumentativas dos enunciados, uma vez que, para Adam (2011, p. 122), "todo enunciado possui um valor argumentativo, mesmo uma simples descrição desprovida de conectores argumentativos".

Adam (2011) afirma que esse triângulo não hierarquiza os três níveis, mas que existe uma relação em que a representação discursiva [C] e a orientação argumentativa [A] estão na mesma linha sendo mediada pela reponsabilidade enunciativa [B].

Em relação à Rd, Adam (2011, p. 114) afirma que "é o interpretante que constrói a $\mathrm{Rd}$ a partir dos enunciados (esquematização), em função de suas próprias finalidades (objetivos, intenções)". Ainda com o autor, entendemos que no momento em que alguém começa a redigir um discurso, seja ele oral ou escrito, ele tem uma intenção a ser posta e pretende que o seu interlocutor seja convencido dessa intenção visada do texto. O conceito de representação discursiva apontado por Adam (2011) está baseado na teoria da lógica natural de Grize (1996), na qual temos o conceito de esquematização e das operações lógico-discursivas. A esquematização para Grize (1996 Apud PASSEGGI, 2001, p. 249) está situada em três imagens: "imagem do locutor: im (A). Imagem do alocutário im (B). Imagem do tema tratado im (T)". Para Passeggi (2001), toda esquematização tem essas imagens em menor ou maior intensidade e chama a do seu interlocutor para uma reconstrução.

Nesse sentido, Rodrigues, Passeggi e Silva Neto (2010) apresentam a noção de Representação discursiva com suas respectivas categorias para os estudos da ATD. 
Propomos, então, aqui, alguns procedimentos de construção semântica da proposição, com base nas operações que a ATD define para o período/sequência descritiva (ADAM, 2008b p. 215-224): tematização (que reinterpretamos como um caso específico de referência / referenciação), aspectualização e relação. Das operações lógicodiscursivas de Grize (1990, 1996), focalizaremos as operações de predicação e Localização espacial e temporal. A conexão, também apresentada por Grize, poderá ser incluída na noção de "relação" de Adam.

Assim, de acordo com Rodrigues, Passeggi e Silva Neto (2010), temos as categorias da referência, a predicação, aspectualização, a relação e a localização. Nesse trabalho, as análises serão por meio da categoria da referência/referenciação que para Rodrigues, Passeggi e Silva neto $(2010$, p.) "diz respeito a toda entidade ou a todo objeto que é nomeado, designado quando se usa um determinado termo ou se cria qualquer situação discursiva". Logo, entendemos referenciação como atividade discursiva (KOCH 2004). Portanto, temos à disposição toda forma de nomeação, renomeação, categorização e recategorização dos referentes, levando em conta o conteúdo contextual e cotextual, tendo em vista as interpretações das representações discursivas.

Após essa discussão teórica, a seguir, nossas análises das $\mathrm{Rds}$ de si dos remanescentes quilombolas na narrativa do lobisomem.

\section{O medo a coragem e a religião dos remanescentes quilombolas de Portalegre/RN}

Nesse capítulo, analisamos as seguintes Rds: de "Medo de ser sorteado para o exército", de "Religiosos" e de "Corajosos". Desse modo, começamos apresentando a Rd Medo de ser sorteado para o exército.

\subsection{Representações discursivas dos remanescentes quilombolas: o medo e o terror da segunda guerra mundial}

As categorias usadas na construção desta Rd são as da localização, da predicação e da referenciação.

Vejamos o trecho do corpus: 
H84: "fazê exercício aqui qué pra quano nóis chegá no ixército num dá

H84: Com medo do ixército... purque no meu tempo... quano tava cum a idade de $303 \mathrm{~d}$ vinte e um ano tĩa quecaí no surtei... né?... pra jurá as arma... $\quad 304 \mathrm{~d}$ $[\ldots]$

... nesse tempo quano caía no surteio

era um clamô de vida... véi... o pessual... vige Maria... era pu mundo se acabá... sê $\quad 309 \mathrm{~d}$ surtiado tudo o mais... primêro lá im casa nóis era três lá im casa... o primêro que hove $\quad 310 \mathrm{~d}$ foi o finado Antõi quera irmão meu... quano caiu no ixército cadê quele foi? ... num foi $311 \mathrm{~d}$ cum medo ... cum medo... ficô que nẽi um criminoso... $312 \mathrm{~d}$ purque o camarada que num fosse ... ficava pió do que um criminoso... acredita? $313 \mathrm{~d}$ Souza, Mendes e Fonseca (2011).

A ideia de ser sorteado para servir ao exército é associada a um momento de medo pelos remanescentes quilombolas, na linha 308d e 309d, como podemos observar na seguinte preposição-enunciado: "nesse tempo quano caía no surteio era um clamô de vida...". Desse modo, a partir desse momento, da localização temporal "nesse tempo", H84 começa a dissertar sobre as possíveis convocações para o exército e como isso afetou o convívio das comunidades quilombolas na época.

Para compreendermos essa $\mathrm{Rd}$ de medo, que visualizamos nas construções cotextuais, é necessário nos debruçarmos nos aspectos contextuais, uma vez que Adam (2011) afirma que os sentidos são construídos de forma co(n)textual. Seguindo os dados disponibilizados por H84, realizamos um cálculo em que a partir da data da construção do e-book (ano 2000) ${ }^{4}$, comparando-a com a idade de H84, descobrimos o contexto do que acontecia no mundo no momento em que este remanescente quilombola tinha 21 anos idade, quando afirma ser o período em que os homens da comunidade, possivelmente, eram sorteados e recebiam a carta de convocação para o exército brasileiro. "quano tava cum a idade de vinte e um ano tĩa que caí no surtei... né?....", linha 303d.

Nessa perspectiva, mostramos, na figura 1, o resultado desses nossos cálculos e a partir destes achados começamos a ver a história dos remanescentes quilombolas de Portalegre sendo desvelada.

FIGURA 1

\begin{tabular}{cc}
\hline Idade de H84 & 84 anos \\
\hline $\begin{array}{c}\text { Ano da gravação da fala dos } \\
\text { remanescentes quilombolas para }\end{array}$ & 2000 \\
\hline
\end{tabular}

\footnotetext{
${ }^{4}$ Sabemos que esse foi o ano em que as gravações foram feitas devido à investigação, junto a dados da UERN, do ano em que o discente Carlos Magno Viana Fonseca cursou, na graduação, a disciplina de Sociolinguística e fez estas gravações e transcrições como requisito de atividade prática da disciplina.
} 
construção do e-book

Ano da convocação para o Exército

segundo $\mathrm{H84}$

Cálculo para chegar ao ano em que H84 tinha 21 anos
21

$84-21=63 / 2.000-63=1937$

Fig 1: Fonte: Paula (2017).

Antes das interpretações, é pertinente uma breve explicação da figura 1. Para chegarmos ao ano de 1937, tomamos como base a idade de H84 = 84 anos, subtraímos 21 , idade que ele afirma ter sido o período de convocação para o exército e, assim, obtivemos o número 63, que subtraímos do ano em que as gravações foram feitas, no caso, o ano 2000, tendo como resultado 1937, exatamente, o ano em que H84 tinha 21 anos de idade, ou seja, o ano de 1937 está inserido em um contexto de conflitos entre alguns países que dois anos depois deflagravam a Segunda Guerra Mundial.

A figura 2 nos revela que H84, quando cita na linha 303d, "quano tava cum a idade de vinte e um ano tĩa quecaí no surtei... né?... pra jurá as arma...”, está se referindo ao ano de 1937, um ano tenso para o mundo. Antes disso, em 1935, a Itália havia invadido a Etiópia; a guerra civil espanhola já tinha começado em 1936, e, no referido ano de 1937, o Japão tinha ocupado Pequim, a antiga capital imperial chinesa. Com essas informações, percebemos que os eventos pré-guerra mundial já ocorriam e, provavelmente, muitas convocações foram feitas pelo exército brasileiro. Nesse sentido, a partir desse texto, compreendemos que as convocações alcançaram as comunidades remanescentes quilombolas, deixando-os perplexos, uma vez que eles associavam essas convocações para o exército ao medo da guerra e da morte.

Nesse período, as informações eram limitadas para as comunidades, tendo em vista que o acesso ao rádio, jornal ou qualquer veículo de informações era apenas para as pessoas com posses. Dessa forma, as poucas condições financeiras dos remanescentes quilombolas faziam com que toda informação chegada a eles fosse apenas do senso comum, gerando, assim, o medo na comunidade ao saber que a qualquer momento uma mãe e um pai poderiam ver seu filho saindo para a guerra sem perspectiva de volta.

As construções textuais "nesse tempo quano caía no surteio era um clamô de vida... véi... [...] era pu mundo se acabá... sê surtiado", feita por H84, nas linhas 308d e 309d demonstram, por meio da predicação, o terror e o medo que ocorriam quando uma pessoa da comunidade era convocada. Podemos perceber as predicações por meio do que Adam (2011) chama de socioleto, "caía no surteio", "era um clamô" e "era pu 
mundo se acabá...", apresentando essa imagem de expressivo medo do ir à guerra dos seus entes queridos.

Durante o discurso, H84 afirma, na linha 311d: "num foi cum medo ... cum medo...". Dessa forma, com a categoria da predicação, interpretamos que alguns remanescentes quilombolas não conseguiam enfrentar esse medo, apresentando, assim, de forma expressiva, esse pavor de poder ser sorteado para o exército, fazendo o uso da repetição da expressão "cum medo" para reforçar a Rd. Ser sorteado para o exército despertava um medo que dividia os homens das comunidades quilombolas, pois o exército causava terror, mas não se apresentar os estigmatizava como criminosos. É essa a interpretação que fazemos da fala de H84, quando, por meio da predicação, afirma, nas linhas 312d e 313d: "ficô que nẽi um criminoso... purque o camarada que num fosse ... ficava pió do que um criminoso...". Assim, as predicações "ficô que nẽi um criminoso" e "ficava pió do que um criminoso" demonstram duas faces desse medo; uma que os homens tinham de ir, mas também que se não fossem servir colocariam sua integridade em jogo, podendo ser considerados desertores da pátria.

Esse medo de ser sorteado para o exército tomou grandes proporções nas comunidades dos remanescentes quilombolas, uma vez que os homens já tentavam, de alguma forma, preparar-se para possíveis convocações. Essa interpretação é possível de ser feita a partir da proposição-enunciado das linhas 273d e 274d, em que H84 afirma: "fazê exercício aqui qué pra quano nóis chegá no ixército num dá trabaio". Nesse sentido, temos as predicações "chegar no ixército" e "num dá trabaio", que se referem a "chegar no exército sem saber de nada", pois eles, supostamente, acreditavam que já deveriam ir servir às forças armadas com alguma habilidade, uma vez que se não tivessem alguma formação iriam dar trabalho ao invés de ser úteis, podendo, também, ser mortos com mais facilidade em algum possível combate.

Na linha 273d, por meio da categoria da referenciação, é possível verificarmos o referente "nóis", que indica a preocupação que era vigente em muitos ou todos os homens das comunidades quilombolas.

A situação de medo, angústia e impotência que esses sujeitos viveram nesse período foi de grande proporção, uma vez que receber uma carta afirmando que foram convocados para servirem ao exército, tendo de deixar suas famílias e ir para um lugar desconhecido, para os campos de batalha, diminuindo, a perspectiva de voltar para o seio de suas famílias. 
A predicação "fazê execícios" por H84, na linha 273d, nos revela o quanto este medo da convocação, e, possivelmente, estar em campo de guerra mudou a rotina dos remanescentes quilombolas, pois segundo o narrador, os homens próximos à idade de 21 anos, dispensavam um tempo do dia para se exercitar, com medo da convocação ocorrer e seu corpo não resistir ao que poderia acontecer no exército ou, até mesmo, na guerra. Estes exercícios, de acordo com H84, eram realizados nas passagens das águas, que chamava de riacho, onde havia areia e, com outros colegas, treinavam sua agilidade para tentar sobreviver às situações de estresse a que poderiam ser submetidos em possíveis combates.

Assim, por meio das categorias semânticas da localização temporal, da predicação e referência/referenciação interpretamos a Rd de medo de ser sorteado para o exército brasileiro, construída na narrativa do lobisomem contada por H84.

Na seção 3.2. continuamos nossas análises, apresentando a Rd de religiosos.

\subsection{Representações discursivas dos remanescentes quilombolas como religiosos}

As categorias usadas para construção da Rd de religiosos, nessa narrativa, são as da referenciação e da predicação.

H84: nesse tempo quano caía no surteio era um clamô de vida... véi... o pessual... vige $308 \mathrm{~d}$ Maria... era pu mundo se acabá... sê surtiado tudo o mais... $309 \mathrm{~d}$ [...]

“vamo fazê ixerciço no corpo... pulá de toda manêra qué pra quano nóis chegá lá num dá $362 d$ trabaio... cumo de fato... foi Jesus que ajudô... 363d $[\ldots]$

o bicho saiu cum ũa roncaria... véi... queu diche... "vige Nossa Sĩóra"... saiu cum ũa $\quad$ 389d roncaria queu fiquei assombrado... eu diche "pronto!"... eu diche ... "cumé queu vô im 390d casa agora?" $391 \mathrm{~d}$ $[\ldots]$

M81: Eu saia... tirava a novena quano acabava a novena eu cansei de vim daculá da $\quad$ 461d capelĩa de São Gonçalo... $\quad$ 462d Souza, Mendes e Fonseca (2011).

Em quatro momentos distintos da narrativa, H84 e M81 usam referentes que constroem a $\mathrm{Rd}$ de religiosos (cristãos católicos), mas também analisamos características de sincretismo religioso e vestígios de manifestações culturais afrodescendentes nesta $\mathrm{Rd}$.

As interpretações são possíveis de ser feitas, primeiro, no momento em que H84 enfatiza o quanto os remanescentes quilombolas sofriam ao ser ou ver um membro da 
comunidade sorteado para servir ao exército. Nesse momento, H84, na linha 308d, usa o vocativo "vige Maria...", expressão usada pelos que professam a religião católica. A mesma situação ocorre quando H84 está tentando mostrar que o ronco do lobisomem era grande. Assim, através do vocativo, H84, na linha 389d, usa a proposição-enunciado “vige Nossa Sĩóra" que se trata de um referente da religião católica.

As manifestações religiosas observadas por meio desses chamamentos à "Maria" mostram características da fé desse sujeito, mostrando o quanto esta santa católica é importante para a prática de suas crenças. A fé atribuída à Maria é reforçada na linha 389d, quando H84 faz uma recategorização da santa, chamando-a de "Nossa Sĩóra", mostrando sua devoção e temor, pois se coloca como submisso, elevando Santa Maria à posição de senhora da vida dele.

O referente "Jesus", citado na linha 363d, junto com a predicação "ajudô", reforça a $\mathrm{Rd}$ de religiosos dos remanescentes quilombolas, pois, a partir dessa preposição-enunciado, entendemos que H84 acredita que foi Jesus quem o ajudou no momento em que lutava com o lobisomem. A partir de uma verificação da recorrência desse referente em todos os inquéritos, entendemos o quanto o catolicismo é forte nas comunidades quilombolas. O referente "Maria" é citado em diversos momentos, categorizado e recategorizado de muitas formas. Assim, esses usos revelam a veneração à "Maria" na prática do cristianismo católico.

O catolicismo é uma religião com significantes manifestações de sincretismo religioso, que são a adaptação de várias crenças na mesma religião. Nesse sentido, durante a parte da narrativa contada por M81, é possível percebermos esses traços, por meio da predicação e da localização espacial. Na linha 461d, verificamos a predicação "tirava a novena", que se trata de uma prática do catolicismo. No entanto, M81 usa, na linha 462d, a localização espacial a "capelĩa de São Gonçalo...”, que trata de um lugar onde faz a veneração a uma imagem de pele negra e, além das missas, novenas e orações feitas a esse santo, também são realizadas festas com uma dança bem específica, semelhante aos rituais de outras religiões, por exemplo, o candomblé. Segundo Sanches e Martins (1999, on-line), “as características atribuídas a esse santo popular aproximam-se bastante das exercidas pelos exús do candomblé”. Com os autores, compreendemos que a dança atribuída a São Gonçalo pelos remanescentes quilombolas teve sua origem nas danças trazidas pelos negros escravos africanos. Neste entendimento, os remanescentes quilombolas de Portalegre/RN, que hoje dançam atribuem o ritual ao santo do catolicismo e não têm mais à sua origem vinda do 
candomblé, fazendo louvores apenas ao santo católico e deixando a verdadeira origem apenas na história.

Isto posto, a análise da $\mathrm{Rd}$ de religiosos nessa narrativa, mostra que, além desses remanescentes serem religiosos praticantes da religião católica, é possível verificarmos vestígios de religiões afrodescendentes inseridas nas suas manifestações de fé.

A seguir, apresentamos construções textuais que expõem a Rd de corajosos.

\subsection{Representações discursivas dos remanescentes quilombolas como corajosos}

A categoria usada para construir essa Rd é a da aspectualização, da referenciação e da predicação.

M81: ... ele tava mermo assim cum as duas mão na calçada... ói... ((incomp)) marreu $\quad 427 \mathrm{~d}$ peguei ũa foice pra metê nesse bicho ... quano a foice desceu quele viu que ia pegá $\quad 428 \mathrm{~d}$ na testa ... pulô caiu lá no mêi do terrêro ... $429 \mathrm{~d}$ $[\ldots]$

aí quano o finado meu pai entrô pra dento ela chegô que caiu no batente da porta ... aí o $\quad$ 469d finado meu pai deu cum o cabo da ispingarda aí o bicho desceu... véi... aí o bicho $\quad 470 \mathrm{~d}$ desceu... desceu ... foi simbora... $471 \mathrm{~d}$ Souza, Mendes e Fonseca (2011).

A figura 4 é referente à parte da narrativa em que M81, esposa de M84, é atacada pelo lobisomem em sua casa. Nesse relato feito por essa senhora, ocorre a referência a três proposições-enunciados que nos faz interpretarmos a Rd de corajosos.

Iniciamos essa análise, a partir do relato de M81, na proposição-enunciado "marreu peguei ũa foice pra metê nesse bicho ...", nas linhas 427d e 428d. Nesse enunciado, por meio do referente "marreu", (junção da conjução "mas" mais o referente "eu") seguido das predicações "peguei ũa foice" e "pra metê nesse bicho ..." podemos interpretar que essa senhora enfrenta o perigo com coragem diante do desconhecido. A construção textual, por meio da referenciação que categoriza o lobisomem de bicho "nesse bicho", deixa clara que ela estava diante de uma situação de atrito com a fera, mas, mesmo assim, não recuou e o enfrentou apenas com uma foice, como podemos verificar por meio da predicação e da referenciação "peguei ũa foice".

Ainda no enunciado "a foice desceu quele viu que ia pegá na testa pulô caiu lá no mêi do terrêro...", na linha 428d, verificamos que M81 apresenta a imagem de coragem ao afirmar, por meio das referenciações e das predicações, "a foice desceu" e 
"ia pegá na testa", que a sua coragem não ficou apenas em ameaças, mas que ocorreu um enfrentamento dela com o lobisomem.

A coragem é também verificada no momento em que M81 afirma na proposiçãoenunciado "o finado meu pai deu cum o cabo da ispingarda aí o bicho desceu...", nas linhas 469d e 470d. Neste enunciado, M81 modifica o referente "meu pai" por meio do modificador "o finado", para deixar claro para seu alocutário que estava fazendo uma menção ao seu pai, já falecido, e que ele também tinha coragem de enfrentar o lobisomem. No seu discurso, ela afirma, por meio da predicação e da referenciação, que seu pai mostrou sua coragem ao enfrentar a fera usando uma espingarda: "deu cum o cabo da ispingarda aí o bicho". Portanto, verificamos a Rd de corajosos nos enunciados construídos por essa senhora.

Assim, findamos nossas análises das $\mathrm{Rd}$ dos remanescentes quilombolas na narrativa do lobisomem.

\section{Conclusão}

O presente trabalho teve como objetivo fazer a análise de representações discursivas na narrativa do lobisomem, contada por remanescentes quilombolas. A narrativa está contida no e-book "A fala de remanescentes quilombolas de Portalegre do Brasil". Nossas análises seguiram a abordagem teórico-metodológica da Análise Textual dos Discursos, com foco nas discussões de Adam (2011). Apresentamos, nesta conclusão, uma síntese dos nossos resultados e as contribuições para os estudos da textualidade, especificamente para a ATD.

A $\mathrm{Rd}$ desencadeada de forma expressiva na narrativa do lobisomem foi a de medo de ser sorteado para o exército brasileiro. Os estudos co(n)textuais em torno dessa $\mathrm{Rd}$ mostraram que os remanescentes quilombolas, hoje, ainda vivos, sentiram os impactos da segunda guerra mundial de forma direta em suas vidas, pois os terrores da guerra chegaram até eles, uma vez que, a qualquer momento, podiam ser convocados para servirem ao exército. Nesse contexto, eles se sentiam impotentes, já que a ida ao exército os deixava sem muitas perspectivas de voltarem com vida, mas a desobediência poderia torná-los desertores da pátria.

Em relação à $\mathrm{Rd}$ de religiosos, os remanescentes quilombolas são expressivamente religiosos, praticantes da religião católica, mas, em algumas construções textuais, percebemos traços da religião afrobrasileira do candomblé. As 
categorias mais relevantes para a interpretação dessa $\mathrm{Rd}$ foram a referenciação e a predicação. A referenciação se faz presente com as diversas formas de referência aos santos do catolicismo e do candomblé. A predicação ocorre com os diversos verbos que materializam a prática religiosa.

Por fim, a Rd de corajosos em que eles mostram, por meio da ficção, a ousadia de enfrentar o sobrenatural, usando ferramentas do seu dia a dia, mas o fio com a realidade mostra o medo que estes sujeitos tiveram de ser usados como soldados durante o período da Segunda Guerra Mundial.

O estudo semântico das Representações discursivas, segundo Rodrigues et al. (2012, p. 298), trata "de procedimentos de textualização gerais e elementares que estão na base da construção de todo texto". Desse modo, entendemos que nossa pesquisa contribui para os procedimentos teórico-metodológicos da ATD, enquanto subdomínio da Linguística de Texto, uma vez que este trabalho busca compreender como os sentidos são construídos a partir de um texto falado interativo.

Esperamos que o tratamento inicial, a partir desse objeto de estudo, possa contribuir com outras pesquisas com outros corpora, em diversos socioletos específicos, para, assim, apropriarmo-nos mais sobre os estudos da textualidade e, assim, compreendermos melhor como os sentidos são construídos, levando em consideração os aspectos cotextuais e contextuais do texto/discurso.

\section{REFERÊNCIAS}

ADAM, J. A Lingüística Textual: introdução à análise textual dos discursos. Trad. RODRIGUES, M. G. S; SILVA NETO, J; PASSEGGI, L; LEURQUIN. E. V. L. F. São Paulo: Cortez, 2011.

GRIZE, J-B. Logique naturelle et communications. Paris: Presses Universitaires de France, 1996.

KOCH, I. G. V. 2004. Introdução à Lingüística Textual. São Paulo: Martins Fontes.

MAZZOLA, R, B. Análise do Discurso: um campo de reformulações. In: MILANEZ, N. SANTOS, J, J. Análise do Discurso: objeto, sujeito e olhares. São Carlos: Claraluz, 2009, p. 7-16.

PASSEGGI, L. A estruturação sintático-semântica dos conteúdos discursivos: categorias descritivas da lógica natural para a linguística. In: PASSEGGI, Luis. OLIVEIRA, Maria do Socorro (Org.). Linguística e Educação: gramática, discurso e ensino. São Paulo: Terceira Margem, 2001.

PASSEGGI, L. et al. A análise textual dos discursos: para uma teoria da produção co(n)textual de sentido. In: LEITE, M. Q; BENTES, A. C. (Org.). Linguística de texto e análise de conversação: panorama das pesquisas no Brasil. São Paulo: Cortez, 2010.

RODRIGUES, M. G. S; PASSEGGI, L; SILVA-NETO, J. G. (Org). "Voltarei. O povo me absolverá...": a construção de um discurso político de renúncia. IN: ADAM, J; 
HEIDEMANN, U; MAIGUENEAU, D. Análises textuais e discursivas: metodologias e aplicações. São Paulo: Cortez, 2012.

RODRIGUES, M. G. S. et al. A carta-testamento de Getúlio Vargas (1882-1954): genericidade e organização textual no discurso político. Filologia e linguística portuguesa. Departamento de Letras Clássicas e Vernáculas. Faculdade de Filosofia, Letras e Ciências Humanas. Universidade de São Paulo, n. 14 (2). São Paulo, FFLCHUSP, 2012.

SANCHES. J, MARTINS. N. Considerações acerca de uma Promessa a São Gonçalo do Amarante no Município de Echaporã-SP. Disponível em http://bmgil.tripod.com/sjnm61.html Acesso em 11 mar de 2018.

SOUZA, M; MENDES, W, V; FONSECA, C, M, V. A fala de remanescentes quilombolas de Portalegre do Brasil. Mossoró: Edições UERN, 2011.

Recebido em 19/03/2018. Aceito em 02/06/2018. 